\title{
CARACTERÍSTICAS HIDRÁULICAS DA EROSÃO EM SULCOS EM UM CAMBISSOLO DO SEMIÁRIDO DO BRASIL ${ }^{(1)}$
}

\author{
Sandro Augusto Bezerra ${ }^{(2)}$, José Ramon Barros Cantalice ${ }^{(3)}$, Moacyr \\ Cunha Filho $^{(4)} \&$ Wagner Luis da Silva Souza ${ }^{(5)}$
}

\begin{abstract}
RESUMO
A erosão em sulcos é formada a partir da concentração do escoamento superficial nas depressões da superfície do terreno, evoluindo para a formação de canais ou ravinas, o que faz aumentar a degradação dos solos pela erosão hídrica. Os objetivos deste trabalho foram avaliar as condições hidráulicas do escoamento em sulcos pré-formados, caracterizando o regime de escoamento, e avaliar mudanças induzidas na geometria desses sulcos. Para isso, um experimento foi realizado num Cambissolo Háplico do sertão pernambucano, município de Serra Talhada, Brasil. Os tratamentos consistiram na aplicação de vazões de 17,5; 47,0; 60,0; 77,0; e 110,0 L min ${ }^{-1}$, com duração de $20 \mathrm{~min}$, em sulcos pré-formados em um solo recém-preparado. O aprofundamento dos sulcos foi dominante no início dos testes. A partir do momento em que o sulco atingiu o solo não revolvido, o processo erosivo, ou seja, a ação da tensão cisalhante, caracterizou-se principalmente pelo alargamento do canal, desgastando com maior proporção a base das paredes laterais dos sulcos. A ação da concentração do escoamento superficial nos sulcos experimentais produziu regimes de escoamento na faixa de transição supercrítico, atestando a ocorrência da erosão em sulcos. O cisalhamento na base do sulco, provocado pelo escoamento, facilitou o desmoronamento nas paredes laterais.
\end{abstract}

Termos de indexação: erosão hídrica, hidráulica do escoamento, regime de escoamento.

\footnotetext{
(1) Parte da Tese de Doutorado do primeiro autor, realizada sob a orientação do segundo autor, no Programa de Pós-Graduação em Ciência do Solo, Universidade Federal Rural de Pernambuco - UFRPE, com recursos do CNPq. Recebido para publicação em maio de 2007 e aprovado em junho de 2010.

(2) Professor substituto da Escola Agrotécnica Federal de Vitória de Santo Antão - EAFVSA. Vitória de Santo Antão (PE). E-mail: sabezerra@hotmail.com

(3) Professor Associado da Departamento de Agronomia, Universidade Federal Rural de Pernambuco - UFRPE. CEP 52171900. Recife (PE). E-mail: cantalic@terra.com.br

(4) Doutorando do Programa de Pós-Graduação em Ciência do Solo, UFRPE. E-mail: moacyr@deinfo.ufrpe.br

(5) Engenheiro-Agrônomo e Mestrando em Ciência do Solo, UFRPE. E-mail: wagneragro@yahoo.com.br
} 


\title{
SUMMARY: HYDRAULIC CHARACTERISTICS OF RILL EROSION INA SEMI- ARID CAMBISSOLO IN BRAZIL
}

\begin{abstract}
Rill erosion begins with the concentration of surface runoff on depressions of soil surface, evolving into the formation of channels or ravine, increasing soil degradation by water erosion. The objectives of this study were to evaluate the hydraulic conditions of the water flow in rills and characterize the water flow regime, and to measure the induced changes in the geometry of the preestablished rills. An experiment was conducted in which outflows of 17.5; 47.0; 60.0; 77.0 and $110.0 \mathrm{~L} \mathrm{~min}^{-1}$ were applied for $20 \mathrm{~min}$ to preformed rills in a Cambissolo Háplico, in Serra Talhada, Pernambuco. The deepening of the rills was dominant at the beginning of the tests. From the moment the rill reached the undisturbed soil, the erosive process, i.e., the action of shear stress, was characterized mainly by the widening of the rill, wearing off the bases of the rill sidewalls. The action of the concentrated water flow in the experimental rills produced flow regimes in the range of supercritical transition, confirming the occurrence of rill erosion. The shear stress at the rill base provoked by the flow facilitated the wearing off of the sidewalls.
\end{abstract}

Index terms: water erosion, hydraulic flow, flow regimes.

\section{INTRODUÇÃO}

O escoamento superficial tem início quando a intensidade de precipitação torna-se maior do que a taxa de infiltração da água no solo, sendo consequência da superação da detenção e da retenção superficial, da interceptação vegetal, da demanda matricial do solo e da evaporação, que são as abstrações hidrológicas dos volumes precipitados. Associado ao escoamento superficial ocorre o transporte das partículas do solo, que sofrem deposição somente quando sua velocidade é reduzida (Griebeler et al., 2001).

A erosão hídrica é um dos principais processos associados à degradação ambiental, podendo ser definida como um processo de desagregação e transporte das partículas do solo causado por agentes erosivos (Griebeler et al., 2001; Römkens et al., 2001). Dessa forma, a erosão reduz a capacidade produtiva das culturas, além de causar sérios danos ambientais, como: assoreamento e poluição das fontes de água (Zartl et al., 2001; Cogo et al., 2003).

A desagregação e o transporte das partículas do solo na erosão em sulcos se dão pela ação das forças hidráulicas provocadas pelo escoamento superficial concentrado nos sulcos, originado pelas chuvas (Polyakov \& Nearing, 2003). A erosão em sulcos constitui-se na segunda fase evolutiva do processo físico da erosão hídrica do solo, que é marcada pela mudança da forma do escoamento. De difuso sobre a superfície do solo, na fase inicial da erosão em entressulcos, o mesmo concentra-se na segunda fase, em pequenas depressões da superfície do solo, chamadas de sulcos de erosão (Cantalice, 2002). Quando isso ocorre, a lâmina de escoamento desenvolve maior tensão de cisalhamento devido ao aumento da sua espessura, elevando, portanto, a capacidade do escoamento em desagregar o solo (Cantalice et al., 2005).
Merrit (1984), observando lâminas de escoamento em ensaios de laboratório, identificou vários estádios no processo de formação dos sulcos. Antes da formação do sulco ocorre um estádio classificado como regime laminar com número de Reynolds $\left(R_{e}\right)<500$. No estádio seguinte, o escoamento já se concentrou em canais bem definidos, caracterizando regime de transição; no terceiro estádio, o sulco apresenta incisões na superfície do solo, na forma de headcuts, processo esse denominado por Merten (2000) de erosão regressiva, que é favorecido pelo escoamento nas laterais dos sulcos, o qual contribui para o aumento destes e avanço dos headcuts (Robinson \& Hanson, 1995).

Segundo Auzet et al. (1993), os sulcos são efetivos na transferência de escoamento a uma longa distância e a deposição pode ser em estradas ou em áreas urbanas, estando sempre associada com o desenvolvimento de uma rede efêmera de canais. Bryan \& Rockwell (1998) relatam que alguns estudos mostram que a taxa de erosão do solo aumenta com o início dos sulcos. Esse aumento no desenvolvimento dos sulcos também tem significado geomorfológico, com implicações potenciais nas encostas e na evolução da rede de drenagem.

A erosão em sulcos é um dos mais importantes tipos de erosão hídrica (Govers \& Rauws, 1986), sendo extremamente severa em regiões onde as chuvas são intensas (Planchon et al., 1987). Segundo Bryan (1987), muitas pesquisas definem sulcos de erosão como microcanais, pequenos o bastante que podem ser removidos por meio de operações de lavoura normal. No entanto, Selby (1994) relata que, como os sulcos existem em áreas onde não há uso contínuo do solo, uma definição mais geral dos sulcos de erosão se faz necessária: são canais com pequenas dimensões, que ocorrem em declives maiores que 2-3\%, podendo 
apresentar conexão com um sistema de drenagem da encosta e ser obliterados entre uma chuva e outra, pelo desmoronamento das paredes laterais, que, assim, excede o transporte de sedimentos do escoamento do canal.

Os objetivos deste trabalho foram avaliar as condições hidráulicas do escoamento em sulcos e caracterizar o regime de escoamento sob condições de sulcos pré-formados sobre solo recém-preparado.

\section{MATERIAL E MÉTODOS}

As avaliações das condições hidráulicas e das relações de erosão em sulcos em solo recém-preparado foram conduzidas na fazenda experimental da Unidade Acadêmica de Serra Talhada da Universidade Federal Rural de Pernambuco - UFRPE, em setembro de 2005. Essa unidade localiza-se na região semiárida do Alto Sertão do Rio Pajeú, a uma altitude de 429 m, com coordenadas geográficas de $7^{\circ} 56$ ' 15 ” de latitude sul e $38^{\circ} 18^{\prime} 45^{\prime}$ de longitude oeste, distando $420 \mathrm{~km}$ de Recife. De acordo com a classificação de Köppen, o clima enquadra-se no tipo Bwh, denominado semiárido, quente e seco, chuvas de verão-outono com pluviosidade média anual de $647 \mathrm{~mm}$ ano-1 e médias térmicas anuais superiores a $25{ }^{\circ} \mathrm{C}$.

A área experimental localizou-se no terço médio de uma pendente, com aproximadamente $80 \mathrm{~m}$ de comprimento e declive médio de 6,5\%. O solo da área é um Cambissolo Háplico de textura média (franco-arenosa) com $596 \mathrm{~g} \mathrm{~kg}^{-1}$ de areia, $216 \mathrm{~g} \mathrm{~kg}^{-1}$ de silte e $188 \mathrm{~g} \mathrm{~kg}^{-1}$ de argila, com densidade do solo de $1,36 \mathrm{~g} \mathrm{~cm}^{-3}$ e teor de matéria orgânica de $17,2 \mathrm{~g} \mathrm{~kg}^{-1}$, na profundidade de 0 a $0,10 \mathrm{~m}$; na camada de 0,10 a $0,20 \mathrm{~m}$, a textura é média (franco-arenosa), com $678 \mathrm{~g} \mathrm{~kg}^{-1}$ de areia, $152 \mathrm{~g} \mathrm{~kg}^{-1}$ de silte e $170 \mathrm{~g} \mathrm{~kg}^{-1}$ de argila, com densidade do solo de 1,32 $\mathrm{g} \mathrm{cm}^{-3}$ e teor de matéria orgânica de $7 \mathrm{~g} \mathrm{~kg}^{-1}$. Essa área anteriormente vinha sendo utilizada com as culturas de milho e feijão, plantadas manualmente por pequenos agricultores somente no período das chuvas, que é o manejo característico da agricultura de subsistência. Nesse manejo de solo, somente a camada superficial até os 0,10 m é mobilizada.

A área experimental foi preparada manualmente, mobilizando o solo na camada superficial até $0,10 \mathrm{~m}$. As parcelas experimentais consistiram em sulcos préformados com o uso de uma enxada, utilizando-se da extremidade cortante e mantendo-se a inclinação natural do terreno. As dimensões dos sulcos foram de $5 \mathrm{~m}$ de comprimento, no sentido da maior pendente, $6 \mathrm{~cm}$ de profundidade e $0,5 \mathrm{~m}$ de largura, delimitados superior e lateralmente pela colocação de chapas metálicas de zinco com $30 \mathrm{~cm}$ de altura, dos quais $15 \mathrm{~cm}$ foram enterrados.

Os 25 sulcos pré-formados foram divididos em cinco blocos de cinco sulcos e imediatamente submetidos aos testes de erosão em sulcos, com a aplicação dos diferentes níveis de vazão de forma casualizada em cada bloco, sendo realizado um teste por vez.

Os tratamentos consistiram na aplicação dos diferentes níveis de vazão, conforme a seguir: tratamento 1-17,5 L min-1; tratamento 2-47 L min $^{-1}$; tratamento 3-60 L min-1; tratamento 4-77 L min-1; e tratamento 5-110 L min-1. Os testes experimentais tiveram duração de 20 min (Cantalice, 2002), com a aplicação das diferentes vazões em cada sulco. As vazões foram determinadas segundo dados de precipitação e períodos de retorno de 100 anos, de acordo com Molinier et al. (1994).

A água foi conduzida aos sulcos, por gravidade e através de mangueira de polietileno calibrada, proveniente de um reservatório com capacidade de $1.000 \mathrm{~L}$, mantido sob carga constante com a água de um reservatório próximo à área experimental. $\mathrm{Na}$ extremidade superior dos sulcos foram enterrados dissipadores de energia na forma de recipientes plásticos circulares, de forma que a borda superior do recipiente ficasse no nível da superfície do solo. Nesses recipientes foram introduzidas as mangueiras condutoras de água, que chegavam aos sulcos pelo transbordamento dos recipientes. Na extremidade inferior dos sulcos foi instalada uma calha coletora metálica, para auxiliar na coleta das amostras de descargas líquida e sólida.

\section{Caracterização hidráulica do escoamento nos sulcos}

As dimensões das seções transversais nos sulcos foram aferidas por intermédio de um perfilômetro, objetivando-se a determinação da área, do perímetro molhado e do raio hidráulico. O perfilômetro constituise de 30 hastes plásticas espaçadas de $0,02 \mathrm{~m}$ e acopladas a uma estrutura retangular de acrílico com 0,8 $\mathrm{m}$ de comprimento e 0,4 $\mathrm{m}$ de altura (Figura 1 ). As medições foram realizadas imediatamente após o início do escoamento e 2 min antes do término dos testes. As medidas foram tomadas a 1,0 e 4,0 m da extremidade superior dos sulcos, conforme descrito a seguir, no início dos testes e 1 min antes do término. Com o perfilômetro nivelado e na posição vertical sobre as chapas metálicas, soltaram-se suavemente as hastes plásticas até a superfície do solo, para em seguida serem fixadas as estruturas. Nesse momento, o perfilômetro era removido para fora da área de testes.

As formas da seção transversal dos sulcos eram retratadas em cartolinas colocadas entre as hastes plásticas e a estrutura de acrílico, com pincel atômico em escala real. Também foi anotada na cartolina, antes de retirar da área dos sulcos, a distância entre as hastes que marcavam a largura da lâmina, que, quando grafadas e combinadas com a seção transversal dos sulcos, forneceram o raio hidráulico.

A velocidade superficial do escoamento foi determinada pela cronometragem do tempo gasto para 


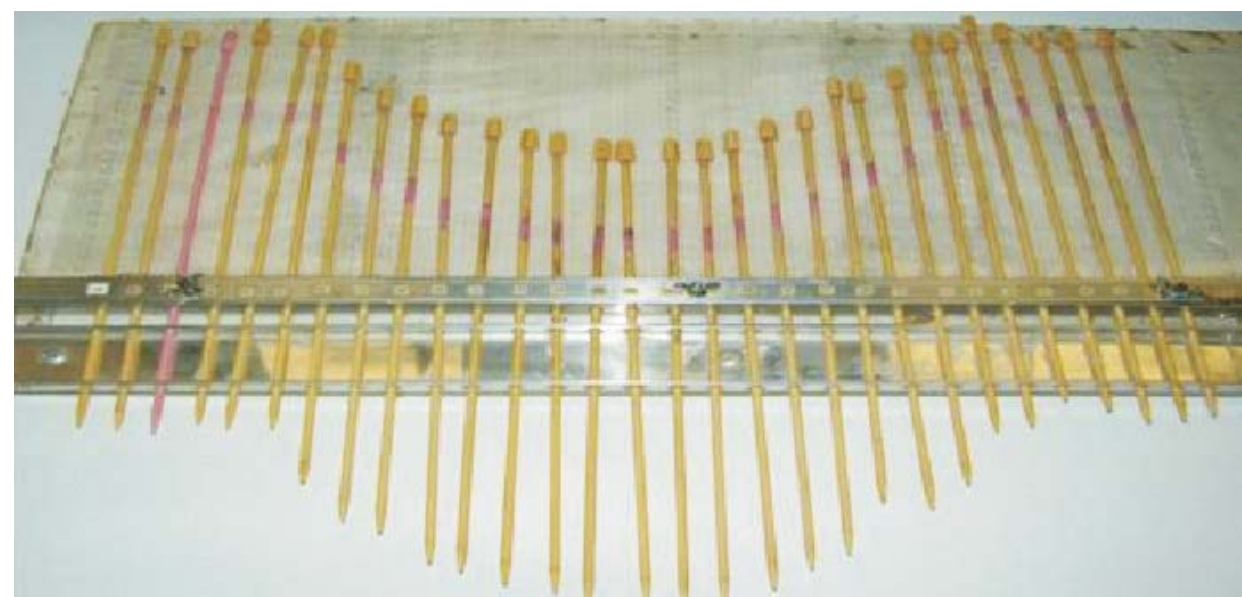

Figura 1. Perfilômetro utilizado para obtenção das seções geométricas dos sulcos de erosão pré-formados em um Cambissolo Háplico do semiárido do Estado de Pernambuco.

que um corante (azul de metileno) percorresse a distância de $3 \mathrm{~m}$ centrais dos sulcos. Os valores de velocidade superficiais assim obtidos foram expressos $\mathrm{em} \mathrm{m} \mathrm{s}^{-1}$. As velocidades superficiais foram tomadas de 3 em 3 min, a partir da formação da lâmina de escoamento. Os valores medidos foram multiplicados por um fator de correção $(\alpha=0,6)$ para se obter a velocidade média do escoamento, tendo em vista a distribuição do perfil de velocidade nos sulcos. O valor de 0,6 tem sido utilizado por diversos autores (Cantalice et al., 2005; Bezerra \& Cantalice, 2006).

As medições de volume líquido e a amostragem para concentração de sedimentos foram efetuadas de $3 \mathrm{em} 3 \mathrm{~min}$. As taxas de descarga líquida foram determinadas pela medição in situ do volume líquido coletado em uma proveta durante dois segundos, sendo expressas em $\mathrm{m}^{3} \mathrm{~s}^{-1}$. As amostras da enxurrada coletadas nas provetas foram acondicionadas em potes e conduzidas ao laboratório, para determinação da concentração de sedimentos.

Para definição das condições hidráulicas do escoamento nos sulcos pré-formados e de sua interação com a superfície do solo, foram determinadas as características hidráulicas descritas a seguir.

O número de Reynolds foi determinado pela relação:

$$
R_{e}=\frac{V R_{h}}{v}
$$

em que $\mathrm{Re}=$ número de Reynolds, adimensional; $\mathrm{V}=$ velocidade média do escoamento $\left(\mathrm{m} \mathrm{s}^{-1}\right) ; R_{\mathrm{h}}=$ raio hidráulico $(\mathrm{m})$; e $v=$ viscosidade cinemática da água $\left(\mathrm{m}^{2} \mathrm{~s}^{-1}\right)$. A grande importância do número de Reynolds é que permite avaliar o tipo do escoamento (a estabilidade do fluxo) e pode indicar se flui de forma laminar (entressulcos) ou turbulento (sulcos).

A viscosidade cinemática $\left(v\right.$, em $\left.\mathrm{m}^{2} \mathrm{~s}^{-1}\right)$ foi determinada conforme expressão dada por Julien (1995). A temperatura da água foi medida por meio de um termômetro em cada uma das vazões aplicadas.

$$
v=\left[1,14-0,031(T-15)+0,00068(T-15)^{2}\right] \times 10^{-6}
$$

O número de Froude (Fr) foi obtido pela expressão:

$$
F_{r}=\frac{V}{\sqrt{\left(g R_{h}\right)}}
$$

em que $V=$ velocidade média do escoamento $\left(\mathrm{m} \mathrm{s}^{-1}\right) ; g=$ aceleração da gravidade $\left(\mathrm{m} \mathrm{s}^{-2}\right)$; e $R_{h}=$ raio hidráulico (m). O número de Froude tem sido proposto como uma constante relacionada com a formação de sulcos. Quando o escoamento alcançar um número de Froude de 1,2 , tem início a formação dos sulcos para solos arenosos (menos coesos), e de 2,8, para solos de textura mais argilosa - mais coesos (Slattery \& Bryan, 1992).

A velocidade de cisalhamento $\left(U_{*}\right)$, foi determinada pela expressão:

$$
U_{*}=\sqrt{\left(g R_{h} S\right)}
$$

em que $g=$ aceleração da gravidade $\left(\mathrm{m} \mathrm{s}^{-2}\right) ; R_{h}=$ raio hidráulico $(\mathrm{m})$; e $S=$ declive da parcela $\left(\mathrm{m} \mathrm{m}^{-1}\right)$, admitindo-se, neste caso, que a declividade da superfície líquida é igual à declividade da parcela.

O número de Reynolds de partícula foi calculado pela expressão:

$$
R_{e}^{*}=\frac{U_{*} d}{v}
$$

em que $d=$ diâmetro representativo do material que constitui o solo, correspondente ao $\mathrm{d}_{50}$.

A rugosidade dos sulcos foi determinada pelo coeficiente de rugosidade de Manning, obtido a partir da expressão:

$$
n=\frac{R_{h}^{2 / 3} S^{1 / 2}}{V}
$$

em que $n=$ coeficiente de rugosidade de Manning $\left(\mathrm{s} \mathrm{m}^{1 / 3}\right) ; R_{h}=$ raio hidráulico $(\mathrm{m}) ; S=$ declividade do sulco $\left(\mathrm{m} \mathrm{m}^{-1}\right)$; e $V=$ velocidade média do escoamento 
$\left(\mathrm{m} \mathrm{s}^{-1}\right)$. A declividade dos sulcos foi tomada pela variação de altura entre dois pontos de distância determinada nos sulcos e expressa $\mathrm{em} \mathrm{m} \mathrm{m}^{-1}$.

O delineamento experimental foi o de blocos casualizados, utilizando-se as médias referentes às cinco repetições dos tratamentos, para comparação entre eles. A análise estatística dos dados de erosão em sulcos foi realizada com o uso do programa estatístico SAS, com aplicação do teste de Tukey a $5 \%$, para comparação das médias.

$\mathrm{Na}$ análise de regressão dos dados utilizou-se o programa computacional Excel, onde foram obtidas as equações ajustadas para cada regressão.

\section{RESULTADOS E DISCUSSÃO}

Durante a realização dos testes, foram feitas observações visuais do processo de formação e desenvolvimento dos sulcos, que permitem melhor entendimento dos resultados obtidos e, portanto, foram descritas e consideradas na análise destes.

Observaram-se os três subprocessos erosivos característicos da erosão em sulcos: a desagregação do solo no perímetro molhado do sulco, o desmoronamento das paredes laterais do sulco (Figura 2a) e a desagregação intensa localizada em pontos de maior turbulência do escoamento, formando desníveis no leito do sulco (Figura 2b). Essa desagregação intensa em pontos localizados, caracterizados pela formação de degraus no leito dos sulcos, foi observada ao longo de todo o teste e em todas as vazões estudadas. Nas maiores vazões, esse processo foi mais intenso e de melhor visualização, formando degraus maiores e que se deslocavam no sentido contrário ao do escoamento.

O aprofundamento dos sulcos foi dominante no início dos testes, ocorrendo rápida remoção da camada superficial do solo, revolvida por ocasião da préformação dos sulcos até a profundidade de $6 \mathrm{~cm}$, que corresponde aproximadamente à camada de solo revolvida pelo preparo realizado pelos agricultores. A partir do momento em que o sulco atingiu o solo não revolvido, o processo erosivo, ou seja, a ação da tensão cisalhante, caracterizou-se principalmente pelo alargamento do canal, desgastando com maior proporção a base das paredes laterais dos sulcos. $\mathrm{O}$ cisalhamento na base do sulco provocou solapamento, facilitando o desmoronamento nas paredes laterais (Figura 3). Assim, as paredes perderam a estabilidade e, em consequência do seu próprio peso, precipitaram-se para o interior dos sulcos, sendo o solo removido pelo escoamento presente no momento do desmoronamento das paredes.

Os valores médios de área, perímetro e raio hidráulico da seção transversal do escoamento, para cada vazão, podem ser verificados no quadro 1. Esses valores representam a média das medições feitas em (a)

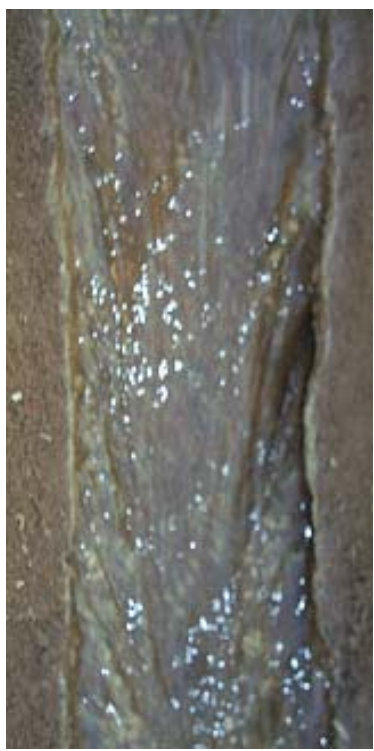

(b)

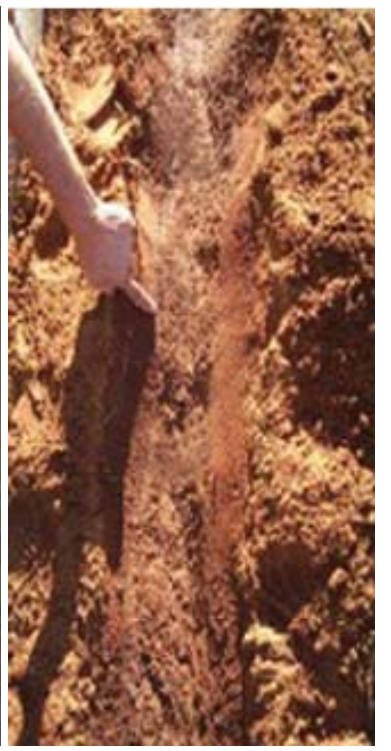

Figura 2. Desmoronamento das paredes laterais do sulco durante a aplicação do teste (a) e desnível formado no leito do sulco (b) em um Cambissolo Háplico textura média do semiárido.

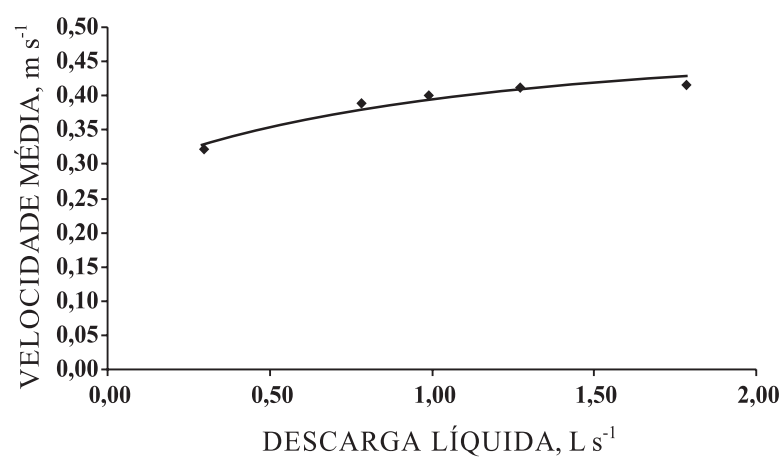

Figura 3. Relação entre a descarga líquida e a velocidade média da água nos sulcos formados em Cambissolo Háplico de textura média do semiárido pernambucano.

Quadro 1. Geometria da seção transversal dos sulcos: área $(\mathrm{A})$, perímetro molhado $\left(\mathrm{P}_{\mathrm{m}}\right)$ e raio hidráulico $\left(R_{h}\right)$, em função das vazões aplicadas nos sulcos em um Cambissolo Háplico textura média do semiárido brasileiro

\begin{tabular}{|c|c|c|c|}
\hline Vazão & $A_{x} 10^{-4}$ & $P_{m}$ & $R_{h \times 10^{-3}}$ \\
\hline $\mathrm{L} \mathrm{min}^{-1}$ & $\mathrm{~m}^{2}$ & 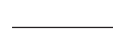 & 1 \\
\hline 17,5 & $2,71 \mathrm{c}$ & $0,137 \mathrm{c}$ & $1,97 \mathrm{c}$ \\
\hline 47,0 & $4,26 \mathrm{~b}$ & $0,171 \mathrm{~b}$ & $2,49 \mathrm{~b}$ \\
\hline 60,0 & $4,95 \mathrm{ab}$ & $0,183 \mathrm{a}$ & $2,69 \mathrm{a}$ \\
\hline 77,0 & $5,00 \mathrm{a}$ & $0,184 \mathrm{a}$ & $2,71 \mathrm{a}$ \\
\hline 110,0 & $5,53 \mathrm{a}$ & $0,193 \mathrm{a}$ & $2,86 \mathrm{a}$ \\
\hline
\end{tabular}

Médias seguidas da mesma letra na mesma coluna não diferem estatisticamente pelo teste de Tukey a $5 \%$. 
dois pontos dos sulcos em dois momentos do teste, em cada uma das cinco repetições. Essas três características dos sulcos variaram significativamente com o aumento da vazão neles aplicada. Entretanto, verificou-se que entre as vazões de 60 e $110 \mathrm{~L} \mathrm{~min}^{-1}$ não houve diferenças significativas entre os valores observados, por conta da não diferenciação dos escoamentos obtidos entre esses níveis de fluxo.

Com base na determinação da velocidade média do escoamento e das descargas líquidas nos sulcos, foi obtida a relação entre descarga líquida e velocidade média do escoamento (Figura 3). Os dados foram ajustados por um modelo potencial dado por:

$$
V=0,3938 Q^{0.15020} \quad \mathrm{r}^{2}=0,95
$$

em que $V=$ velocidade média do escoamento $\left(\mathrm{m} \mathrm{s}^{-1}\right) \mathrm{e}$ $Q=$ descarga líquida dos sulcos $\left(\mathrm{L} \mathrm{s}^{-1}\right)$.

Essa relação foi determinada por Cantalice et al. (2005) para um Argissolo. Esses autores obtiveram um expoente de 0,32 e um coeficiente de 0,33 para esse modelo.

O aumento da velocidade média do escoamento com a elevação da vazão aplicada nos sulcos proporciona a quebra de grandes agregados (torrões) que são formados durante o preparo da área para a implantação de culturas e o consequente transporte das partículas individualizadas a partir desse momento, implicando maiores perdas de solo. Como já discutido, o aumento da vazão causa danos às paredes laterais dos sulcos $\mathrm{e}$, consequentemente, aumento no perímetro da seção transversal, e a concentração desse escoamento em canais provoca maior transporte de sedimento, que é depositado em áreas impróprias ao cultivo e, ou, causando assoreamento nos cursos d'água.

Nas figuras 4 e 5 são apresentadas as relações entre as descargas líquidas $\left(\mathrm{L} \mathrm{s}^{-1}\right)$ e, respectivamente, o perímetro molhado $\left(\mathrm{P}_{\mathrm{m}}\right)$ e o raio hidráulico $\left(\mathrm{R}_{\mathrm{h}}\right)$. As equações exponenciais ajustadas estão relacionadas a seguir e constituem uma alternativa para que possam ser estimadas as dimensões da seção transversal dos sulcos de erosão.

$$
\begin{array}{ll}
P_{m}=0,1307 e^{0,2624 Q} & \mathrm{r}^{2}=0,97 \\
R_{h}=0,0018 e^{0,268 Q} & \mathrm{r}^{2}=0,88
\end{array}
$$$$
\mathrm{e}
$$

em que $P_{m}=$ perímetro molhado (m); $Q=$ descarga líquida $\left(\mathrm{L} \mathrm{s}^{-1}\right) ; R_{h}=$ raio hidráulico $(\mathrm{m})$; e $e=$ base do logaritmo natural.

A partir da determinação da geometria das seções transversais dos sulcos (raio hidráulico, perímetro molhado e área) e das variáveis hidráulicas de descarga líquida e velocidade média do escoamento, foram determinadas as demais variáveis hidráulicas que caracterizaram o escoamento superficial nos sulcos para as vazões aplicadas.

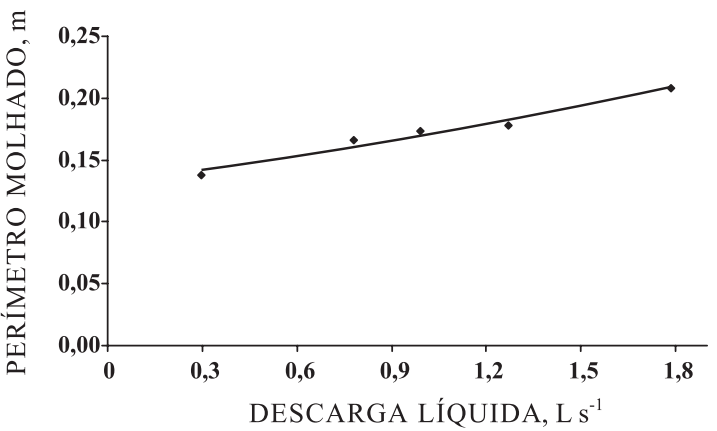

Figura 4. Relação entre a descarga líquida e o perímetro molhado na erosão em sulcos. Média de cinco repetições.

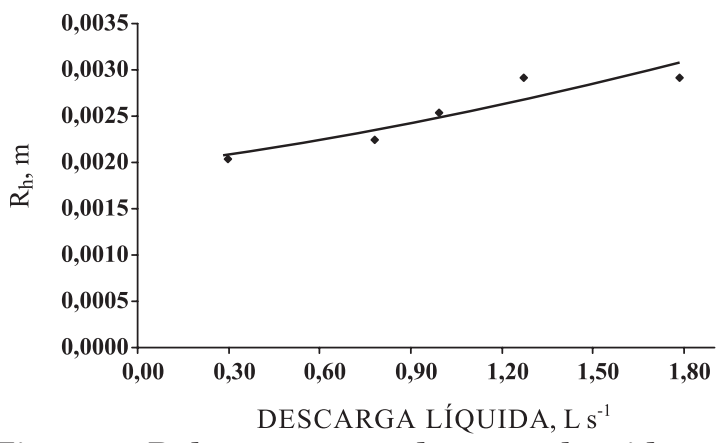

Figura 5. Relação entre a descarga líquida e o raio hidráulico na erosão em sulcos. Média de cinco repetições.

Constam no quadro 2 as condições hidráulicas médias dos escoamentos superficiais obtidos nos sulcos. Observou-se que os regimes de escoamento para todas as vazões aplicadas, de 17,5 a $110 \mathrm{~L} \mathrm{~min}^{-1}$, com os valores de $R_{e}$ entre 1.125 a 2.031 e $F_{r}>1$, refletem um escoamento na faixa de transição rápido (Bezerra et al., 2002; Barcelos et al., 2004; Cantalice et al., 2005).

Apesar da diferença significativa entre os valores dos números de Reynolds (Quadro 2), o regime de escoamento (transição) continua o mesmo, uma vez que a faixa de mudança de um regime de escoamento para outro é muito extensa. Nota-se que o número de Froude, acima de 2 em todas as vazões aplicadas, evidencia a formação dos sulcos, por ser superior ao valor de 1,2 sugerido por Slattery \& Bryan (1992) para o início de formação de sulcos.

A velocidade de cisalhamento $\left(U_{*}\right)$, que, segundo alguns autores, está relacionada com o desenvolvimento inicial dos sulcos, apresentou valores que variaram de 0,03 a $0,04 \mathrm{~m} \mathrm{~s}^{-1}$. O limite preciso do desenvolvimento inicial dos sulcos varia muito com as características do solo (Bryan, 2000). Os valores encontrados por outros autores são da ordem de 0,030 a $0,035 \mathrm{~m} \mathrm{~s}^{-1}$, segundo Govers (1985), e de 0,05 a $0,07 \mathrm{~m} \mathrm{~s}^{-1}$, conforme Merz \& Bryan (1993). Para Rauws (1987), velocidades de cisalhamento acima de $0,032 \mathrm{~m} \mathrm{~s}^{-1}$ atestam a ocorrência de eventos em regime supercrítico. 
Quadro 2. Características hidráulicas médias do escoamento nos sulcos em um Cambissolo Háplico textura média do semiárido brasileiro

\begin{tabular}{cccccc}
\hline \multirow{2}{*}{ Variável hidráulica } & \multicolumn{5}{c}{ Vazões aplicadas, L min $^{-1}$} \\
\cline { 2 - 5 } & $\mathbf{1 7 , 5}$ & $\mathbf{4 7}$ & $\mathbf{6 0}$ & $\mathbf{7 7}$ & $\mathbf{1 1 0}$ \\
\hline $\mathrm{Q}\left(\mathrm{L} \mathrm{s}^{-1}\right)$ & $0,297 \mathrm{c}$ & $0,781 \mathrm{~b}$ & $0,992 \mathrm{ab}$ & $1,272 \mathrm{ab}$ & $1,786 \mathrm{a}$ \\
$\mathrm{V}\left(\mathrm{m} \mathrm{s}^{-1}\right)$ & $0,489 \mathrm{c}$ & $0,573 \mathrm{~b}$ & $0,603 \mathrm{a}$ & $0,605 \mathrm{a}$ & $0,627 \mathrm{a}$ \\
$\mathrm{S}\left(\mathrm{m} \mathrm{m}^{-1}\right)$ & $0,063^{\mathrm{ns}}$ & $0,061^{\mathrm{ns}}$ & $0,056^{\mathrm{ns}}$ & $0,059^{\mathrm{ns}}$ & $0,057^{\mathrm{ns}}$ \\
$\mathrm{R}_{\mathrm{e}}(\mathrm{adm})$ & $1125,25 \mathrm{c}$ & $1714,33 \mathrm{~b}$ & $1927,08 \mathrm{ab}$ & $1950,72 \mathrm{a}$ & $2031,54 \mathrm{a}$ \\
$\mathrm{F}_{\mathrm{r}}(\mathrm{adm})$ & $2,31^{\mathrm{ns}}$ & $2,48^{\mathrm{ns}}$ & $2,46^{\mathrm{ns}}$ & $2,52^{\mathrm{ns}}$ & $2,49^{\mathrm{ns}}$ \\
$n\left(\mathrm{~s} \mathrm{~m}^{-1 / 3}\right)$ & $0,00808^{\mathrm{ns}}$ & $0,00792^{\mathrm{ns}}$ & $0,00761^{\mathrm{ns}}$ & $0,00776^{\mathrm{ns}}$ & $0,00767^{\mathrm{ns}}$ \\
$\mathrm{d}_{5}(\mathrm{~mm})$ & $0,1076 \mathrm{~b}$ & $0,1264 \mathrm{ab}$ & $0,1158 \mathrm{ab}$ & $0,1243 \mathrm{ab}$ & $0,1427 \mathrm{a}$ \\
$\mathrm{R}_{\mathrm{e}}^{*}(\mathrm{adm})$ & $4,36 \mathrm{~b}$ & $5,89 \mathrm{ab}$ & $5,26 \mathrm{ab}$ & $5,81 \mathrm{ab}$ & $6,49 \mathrm{a}$ \\
$U_{*}\left(\mathrm{~m} \mathrm{~s}^{-1}\right)$ & $0,0350 \mathrm{~b}$ & $0,0386 \mathrm{ab}$ & $0,0386 \mathrm{ab}$ & $0,0394 \mathrm{a}$ & $0,0400 \mathrm{a}$ \\
$\tau\left(\mathrm{N} \mathrm{m}^{-2}\right)$ & $1,23 \mathrm{a}$ & $1,49 \mathrm{a}$ & $1,50 \mathrm{ab}$ & $1,55 \mathrm{ab}$ & $1,60 \mathrm{~b}$ \\
\hline
\end{tabular}

Médias seguidas da mesma letra na mesma linha não diferem entre si pelo teste de Tukey a 5\%. ns: não significativo; Q, descarga líquida; $\mathrm{V}$, velocidade média; $\mathrm{S}$, declive; $\mathrm{R}_{\mathrm{e}}$, número de Reynolds; $\mathrm{F}_{\mathrm{r}}$, número de Froude; $n$, coeficiente de rugosidade de Manning; $\mathrm{R}_{\mathrm{e}}^{*}$, Reynolds de partícula; $\mathrm{d}_{50}$, diâmetro da partícula; $U_{*}$, velocidade de cisalhamento; e $\tau$, tensão de cisalhamento.

A rugosidade hidráulica do escoamento, obtida pelo coeficiente de Manning, não apresentou variação significativa com o aumento da vazão aplicada aos sulcos. A rugosidade hidráulica dos sulcos representa a soma da rugosidade das partículas e agregados do solo (n') e da rugosidade de forma dos sulcos (n'). Os valores na ordem de $10^{-3}$ mostram a mínima presença de agregados em superfície, caracterizando baixos valores de rugosidade hidráulicos e refletidos pelo diâmetro médio do sedimento erodido $\left(\mathrm{d}_{50}\right)$, que variou de 0,1076 a 0,1427 $\mathrm{mm}$ (Quadro 2).

No trabalho realizado por Cantalice et al. (2005) com um Argissolo Vermelho distrófico recém-preparado, sem cobertura e declive médio de $0,07 \mathrm{~m} \mathrm{~m}^{-1}$, verificou-se que o diâmetro médio do sedimento produzido pela erosão em sulcos foi de 0,238 a $0,270 \mathrm{~mm}$. Os menores valores de $\mathrm{d}_{50}$ obtidos evidenciam a estrutura menos desenvolvida do Cambissolo Háplico, traduzida na forma do menor diâmetro do sedimento, em relação ao Argissolo estudado por Cantalice et al. (2005).

Os valores de Reynolds de partículas para um diâmetro característico $d_{50}$ entre 4 e 6,5 atestam a ocorrência de regime de escoamento de transição, que, segundo Julien (1995), situa-se entre $4<\mathrm{R}_{\mathrm{e}} *<70$. No trabalho de Cantalice et al. (2005), os valores de Reynolds de partículas na ordem de 20 a 52 também caracterizaram uma superfície hidráulica de transição para todos os tratamentos. Apesar de o $d_{50}$ para a maior vazão aplicada ter sido diferente dos demais níveis de vazão, isso não foi suficiente para alterar a condição de rugosidade da superfície do solo de acordo com o Reynolds de partícula $\left(\mathrm{R}_{\mathrm{e}}{ }^{*}\right)$, que se manteve na faixa de transição.

\section{CONCLUSÕES}

1. A concentração do escoamento superficial nos sulcos experimentais produziu regimes de escoamento na faixa de transição supercrítico, caracterizando a ocorrência da erosão em sulcos.

2. O cisalhamento na base do sulco provocado pelo escoamento facilitou o desmoronamento nas paredes laterais, em relação às crescentes vazões aplicadas, com consequente elevação da área, do perímetro molhado e do raio hidráulico dos sulcos experimentais.

\section{LITERATURA CITADA}

AUZET, A.V.; BOIFFIN, J.; PAPY, F.; LUDWIG, B. \& MAUCORPS, J. Rill erosion as a function of the characteristics of cultivated catchments in the North of France. Catena, 20:41-62, 1993.

BARCELOS, A.A.; BOFFO, C.H.; BORGES, A.L.O. \& BELLINASO, T.B. Adequação de equações de transporte de sedimentos para estudos de erosão em meio coesivo. In: ENCONTRO NACIONAL DE ENGENHARIA DE SEDIMENTOS, 6., Vitória, 2004. Anais... Vitória, 2004. p.109-113.

BEZERRA, S.A. \& CANTALICE, J.R.B. Erosão entre sulcos em diferentes condições de cobertura do solo, sob cultivo da cana-de-açúcar. R. Bras. Ci. Solo, 30:565-573, 2006.

BEZERRA, S.A.; CANTALICE, J.R.B \& TARQUI, J.L.Z. Características do escoamento superficial e taxas de erosão em uma área sob cultivo agrícola. In: ENCONTRO NACIONAL DE ENGENHARIA DE SEDIMENTOS, 5., São Paulo, 2002. Anais. São Paulo, ABRH, 2002. p.403411.

BRYAN, R.B. Soil erodibility and processes of water erosion on hillslope. Geomorphology, 32:385-415, 2000.

BRYAN, R.B. \& ROCKWELL, D.L. Water table control on rill and implications for erosional response. Geomorphology, 23:151-169, 1998.

BRYAN, R.B. Processes and significance of rill development. Catena, 8:1-15, 1987. 
CANTALICE, J.R.B.; CASSOL, E.A.; REICHERT, J.M. \& BORGES, A.L.O. Hidráulica do escoamento e transporte de sedimentos em sulcos em solo franco-argilo-arenoso. R. Bras. Ci. Solo, 29:597-607, 2005.

CANTALICE, J.R.B. Escoamento e erosão em sulcos e em entressulcos em distintas condições de superfície do solo. Porto Alegre, Universidade Federal Rural do Rio Grande do Sul, 2002. 141p. (Tese de Doutorado)

COGO, N.P.; LEVIEN, R. \& SCHWARZ, R.A. Perdas de solo e água por erosão hídrica influenciadas por métodos de preparo, classes de declive e níveis de fertilidade do solo. R. Bras. Ci. Solo, 27:743-753, 2003.

GOVERS, G. \& RAUWS, G. Transporting capacity of overland flow on plane and on irregular beds. Earth Surface Proc. Landforms, 11:515-524, 1986.

GOVERS, G. Selectivity and transport capacity of thin layer flows in relation to rill erosion. Catena, 12:35-39, 1985.

GRIEBELER, N.P.; PRUSKI, F.F.; MARTINS JÚNIOR, D. \& SILVA, D.D. Avaliação de um modelo para a estimativa da lâmina máxima de escoamento superficial. R. Bras. Ci. Solo, 25:411-417, 2001.

JULIEN, P.Y. Erosion and sedimentation. Melbourne, Cambridge University Press, 1995. 280p.

MERTEN, G.H. Dinâmica da erosão em sulcos alterada pelo incremento da descarga sólida. Porto Alegre, Instituto de Pesquisas Hidráulicas, Universidade Federal do Rio Grande do Sul, 2000. 116p. (Tese de Doutorado)

MERRITT, E. The identification of four stages during microrill development. Earth Surface Proc. Landforms, 9:493496, 1984
MERZ, W. \& BRYAN, R.B. Critical conditions for rill initiation on sandy loam brunisol: Laboratory and field experiments in southern Ontorio, Canada. Geoderma, 57:357-385, 1993.

MOLINIER, M.; ALBUQUERQUE, C.H.C. \& CARDIER, E. Análise de pluviometria e isoietas homogeneizadas do nordeste brasileiro. Recife, Sudene, 1994. 58p. (Hidrologia, 32)

PLANCHON, O.; FRITSCH, E. \& VALENTIN, C. Rill development in a wet savannah environment. Catena, 8:55-70, 1987.

POLYAKOV, V.O. \& NEARING, M.A. Sediment transport in rill flow under deposition and detachment conditions. Catena, 51:33-43, 2003.

RAUWS, G. Hydraulics and soil mechanical aspects of rill generation on agricultural soils. Catena, 8:1-15, 1987.

ROBINSON, K.M. \& HANSON, G.J. Large-scale headcut erosion testing. Trans. Am. Soc. Agric. Eng., 38:429-434, 1995.

RÖMKENS, M.J.M.; HELMING, K. \& PRASSAD, S.N. Soil erosion under different rainfall intensities, surface roughness, and soil water regimes. Catena, 456:103-123, 2001.

SELBY, M.J. Hillslope sediment transport and depositional In: PYE, K. Sediment transport and depositional processes. Oxford, Osney Mead, 1994. 397p.

SLATTERY, M.C. \& BRYAN, R.B. Hydraulics conditions for rill incision under simulated rainfall: A laboratory experiment. Earth Surface Proc. Landforms, 17:127-146, 1992.

ZARTL, A.S.; KLIK, A. \& HUANG, C. Soil detachment and transport processes from interrill and rill areas. Phys. Chem Earth, 26:25-26, 2001. 